\title{
Associations between calf mortality during days 1 to 90 and herd-level cow and production variables in large Swedish dairy herds
}

\author{
M. Torsein, ${ }^{*} \dagger^{1}$ M. Jansson-Mörk, $\ddagger$ A. Lindberg, $\S$ C. Hallén-Sandgren,\# and C. Berg† \\ *Swedish Animal Health Service, Uddetorp Röda Huset, SE-532 96 Skara, Sweden \\ †Department of Animal Environment and Health, Swedish University of Agricultural Sciences, PO Box 234, SE-532 23 Skara, Sweden \\ ¥Växa Sverige, PO Box 30204, SE-104 25 Stockholm, Sweden \\ $\S$ Swedish Zoonosis Centre, National Veterinary Institute, SE-751 89 Uppsala, Sweden \\ \#DeLaval International AB, PO Box 39, SE-147 21 Tumba, Sweden
}

ABSTRACT

The aim of the study was to describe large Swedish dairy herds with high and low mortality risk in calves during the first $90 \mathrm{~d}$ of life, using herd-level data, and to evaluate if high calf mortality risk is associated with other herd-level management variables that influence cow health. A total of 57 Swedish dairy herds met the inclusion criteria of affiliation to the Swedish official milk recording scheme, herd size of $\geq 140$ and $\geq 160$ cows in 2008/2009 and 2009/2010, and calf mortality risks, classified as high (HM; calf mortality risk at least $3.5 \%$ in $2008 / 2009$ and $5.5 \%$ in $2009 / 2010$; $\mathrm{n}=28$ ) or low (LM; calf mortality risk less than $<1.5 \%$ in $2008 / 2009$ and 2009/2010; $\mathrm{n}=29$ ), and were thus included in the study. The data used in this study were collected from the Swedish Dairy association during the milking year 2009/2010. For LM herds, the calf mortality risk ranged from 0 to $1.46($ median $=0.66)$ in 2008/2009 and from 0 to 1.48 (median $=0.67$ ) in 2009/2010. For HM herds, the calf mortality risk ranged from 3.57 to 11.52 $($ median $=6.15)$ in $2008 / 2009$ and from 5.88 to 18.23 (median $=8.39)$ in $2009 / 2010$. Median age at death was $28 \mathrm{~d}$ for HM and $37 \mathrm{~d}$ for LM herds. Associations between type of herd (HM or LM) and the production variables were evaluated using multi-correspondence analysis and logistic regression models covering the areas "mortality and culling," "health," "herd/production variables," and "fertility." Herds with HM risks during d 1 to 90 were associated with higher on-farm mortality rate in cows, lower average milk yield, higher incidence of antibiotic treatment, and a higher proportion of purchased animals. These results indicate that herds with HM risk during d 1 to 90 have coexisting issues concerning cow management and health. Future research is needed to evaluate if identifying HM herds and working with advisory and preventive manners at these herds

Received January 15, 2014.

Accepted May 24, 2014.

${ }^{1}$ Corresponding author: Maria.Torsein@svdhv.org also can be positive for a reduction of on-farm mortality and antibiotic usage, which are important issues from a global perspective.

Key words: antibiotic, on-farm mortality, epidemiology, herd health, risk

\section{INTRODUCTION}

In Sweden, the number of dairy herds is steadily decreasing, whereas the mean number of cows per herd is increasing (Swedish Dairy Association, 2012). In this population, calf mortality risk during the first 3 mo in life has previously been reported as low: 2.6 and 3.1\% reported by Olsson et al. (1993) and Svensson et al. (2006), respectively. However, Gidekull et al. (2006) indicated that mortality risk was higher in Swedish dairy herds with $\geq 150$ cows. This trend raises questions about possible animal welfare consequences, as associations between larger herd size and high calf mortality have been reported in several studies (Lance et al., 1992; Nielsen et al., 2002; Gulliksen et al., 2009), even though the opposite (Jenny et al., 1981) or little association (James et al., 1984) has also been reported.

Ortiz-Pelaez et al. (2008) concluded that an increase in calf mortality could be a starting point for targeted welfare inspections, as high-mortality herds could have impaired animal welfare. Another effect of high calf mortality is economic losses due to costs associated with treatment and control of disease preceding death or affecting calves that survive, costs for new replacement heifers (Wathes et al., 2008), and risk of introduction of infectious diseases with new animals to the herd (Maunsell and Donovan, 2008).

Many studies on calf mortality focus on risk factors on an individual (calf) level and also on herd-level risk factors for disease. It is well established that management practices affect morbidity and mortality in dairy calves (Kehoe et al., 2007). Because larger dairy herds is a fairly new feature in Sweden, little is known about their management and structure and its effect on calf mortality, although a recent study on risk factors for 
calf mortality in large dairy herds in Sweden has been performed, indicating that gastrointestinal disorders and inadequate supply of vitamins can play a role for calf mortality (Torsein et al., 2011).

The aim of the present study was, therefore, to describe large Swedish dairy herds with high and low mortality risk in calves during the first $90 \mathrm{~d}$ of life, using herd-level data, and to evaluate if high calf mortality risk is associated with other herd-level management variables that influence cow health.

\section{MATERIALS AND METHODS}

\section{Study Design and Selection of Herds}

The study was designed as a case-control study and the dependent variable in all statistical models was the type of herd. The herds were classified as case (herds with high calf mortality risk; HM) or control herds (herds with low calf mortality risk; LM) based on their average mortality risk during the past $2 \mathrm{yr}$ in calves 1 to $90 \mathrm{~d}$ old (the day of birth is referred to as $\mathrm{d} 0$ ). Mortality risks were calculated based on data from the Swedish official milk recording scheme (SOMRS) at the Swedish Dairy Association (Stockholm, Sweden). The Swedish Dairy Association uses a "milking year," ranging from September 1 to August 31, and this classification is used hereafter and referred to as 2008/2009, 2009/2010, and so on. To be classified as an LM herd, the average mortality risk in 1- to 90-d-old calves should have been $<1.5 \%$ in 2008/2009 and 2009/2010, and to be classified as an HM herd, the corresponding calf mortality should have been at least $3.5 \%$ in $2008 / 2009$ and $5.5 \%$ in 2009/2010. The cut-off point for calf mortality risks used in this study was set to correspond to a recent study on calf mortality in large Swedish dairy herds (Torsein et al., 2011). The primary inclusion criteria were (1) affiliation with SOMRS and (2) herd size of $\geq 140$ and $\geq 160$ cows in $2008 / 2009$ and $2009 / 2010$, respectively, and they were met by 178 herds. Of those, 57 herds ( $28 \mathrm{HM}$ and $29 \mathrm{LM}$ ) met the final inclusion criteria with regard to calf mortality and were, thus, included in the study.

\section{Data}

Information on all Swedish dairy herds that met the inclusion criteria were obtained from the Cattle Database at the Swedish Dairy Association. The Cattle Database provided data on herd characteristics, such as housing system and herd size, and individual cow data such as disease events and dates for entering or leaving the herd (Olsson et al., 2001). Potential explanatory variables at the herd level were selected to reflect the herd status regarding fertility, health, herd dynamics, mortality, and culling. Continuous potential explanatory variables are listed in Table 1 and categorical variables in Table 2. All variables were calculated based on data from the year 2009/2010.

Data Editing. Herd calf mortality in 2008/2009 and 2009/2010, respectively, was calculated as in Equation 1 :

Mortality risk $=$ no. of dead calves 1 to $91 \mathrm{~d}$ of age during the period no. of calves 1 to $91 \mathrm{~d}$ of age during the period (no. of sold calves and calves $<91 \mathrm{~d}$ of age at the end of the period $/ 2$ )

Overall culling rate, culling rate for first-parity cows, on-farm mortality in cows, and incidence of total systemic antimicrobial treatments were calculated according to Equation 2:

$$
\begin{aligned}
& \text { Incidence rate }= \\
& \frac{\text { no. of cases during the time period }}{\text { total cattle-time at risk during the time period }} .
\end{aligned}
$$

The number of cases include the number of veterinarian-reported antimicrobial treatments (antimicrobials for systemic use), culled cows, culled first-parity cows, and dead/euthanized cows. Total cattle-time is the total number of cow-days during the time period investigated for the herd (i.e., the sum of all of the days at risk for all cows in a herd).

Stillbirth and stillbirth in heifers were calculated as the number of total stillbirths divided by the total number of born calves, and stillbirths in heifers divided by the number of born calves from heifers, respectively. The logarithmic bulk milk SCC (BMSCC) was calculated according to Equation 3:

$$
\begin{aligned}
& \log (\text { BMSCC })= \\
& \log \left(\frac{\sum \text { daily milk yield } \times \text { SCC from monthly test milkings for all cows }}{\sum \text { daily milk yield from monthly test milkings for all cows }}\right) .
\end{aligned}
$$

The proportion of cows with a high probability of having mastitis was estimated using the udder health score (UHS), which is a measure of the udder health of an individual cow based on 3 consecutive test milkings (Brolund, 1990). The UHS expresses the probability that a cow has mastitis on a scale from 0 to 9; the higher score, the higher the probability of mastitis. The average annual proportion of cows with UHS 6 to 9 was 
Table 1. Initial list of continuous herd-level explanatory variables in a study of risk factors for high calf mortality in 57 Swedish dairy herds ${ }^{1}$

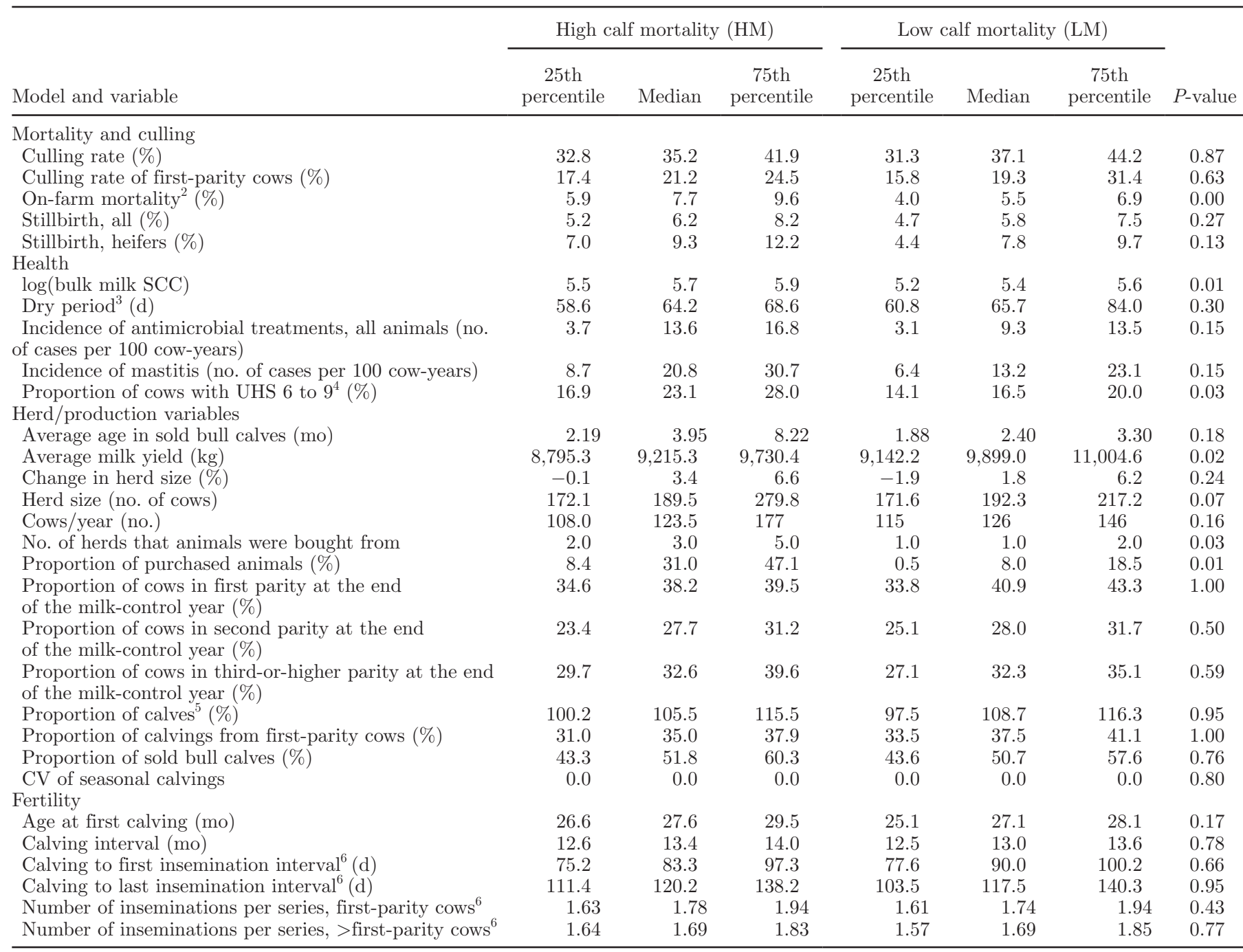

${ }^{1}$ Variables with $P<0.2$ in the univariable analysis were included in the multivariable analysis.

${ }^{2}$ Dead and euthanized cows.

${ }^{3}$ Missing for $1 \mathrm{HM}$ and $2 \mathrm{LM}$ herds.

${ }^{4} \mathrm{UHS}=$ udder health score.

${ }^{5}$ Calculated as a proportion based on the average number of cows in the herd; if the herd puts in more heifers, then values can exceed 100.

${ }^{6}$ Missing for 1 HM herd.

Table 2. Initial list of categorical herd-level explanatory variables (number of herds) in a study of risk factors for high calf mortality in 57 Swedish dairy herds ${ }^{1}$

\begin{tabular}{llrrc}
\hline Variable & Class & $\begin{array}{c}\text { High } \\
\text { mortality }\end{array}$ & $\begin{array}{c}\text { Low } \\
\text { mortality }\end{array}$ & $P$-value \\
\hline Housing & Freestall with automatic milking & 7 & 5 & 0.66 \\
& Freestall with conventional milking & 18 & 19 & \\
Breed & Tie-stall & 3 & 5 & \multirow{2}{*}{0.53} \\
& Mixed/other & 13 & 14 & \\
Management type & Swedish Holstein & 2 & 11 & - \\
& Swedish Red & 28 & 5 & \\
& Conventional herd & 26 & 3 & \\
\hline
\end{tabular}

${ }^{1}$ Variables with $P<0.2$ in the univariable analysis were tested for inclusion in the multivariable analysis. 
calculated as the total number of UHS 6 to 9 divided by the total number of calculated UHS (i.e., 1 cow can have up to 12 UHS during $1 \mathrm{yr}$ ).

Calves born and bull calves sold was estimated as a proportion of herd size and calves from first-parity cows was estimated as a proportion of born calves. The proportional increase in herd size during 2009/2010 was calculated to reflect steady-state or expanding herd as the average herd size in 2009/2010 divided by the average herd size in 2008/2009. The number of other herds that the herd purchased animals from during 2009/2010 was estimated by comparing the herd identity with the birth herd identity in animals entering the herd during the year 2009/2010. Purchased animals were calculated as a proportion of herd size. The variables "number of herds that the herd purchased animals from" and "proportion of purchased animals" were chosen to reflect the risk of introduction of infectious disease in the herd. The coefficient of variation for monthly calvings was used as a measure of seasonality of calvings.

Herds with at least $80 \%$ purebred Swedish Holstein or Swedish Red cattle were categorized as Swedish Holstein herds or Swedish Red herds, respectively. Remaining herds were categorized as mixed/other breed. Housing system was categorized as freestalls with automatic milking, freestalls with conventional milking, or tie-stalls with pipeline milking.

Data Analysis. Data editing, descriptive statistics, and analyses were performed in Stata software (version 12; StataCorp LP, College Station, TX). Factors affecting the likelihood of being a herd with high or low calf mortality were evaluated using logistic regression. All explanatory variables $(\mathrm{n}=33)$ were first screened using univariable logistic regression models, and variables associated with type of herd at $P<0.20$ ( $\mathrm{n}=$ 13) were considered for multivariable analysis. Correlations between variables qualifying for inclusion in the multivariable analyses were assessed using Spearman rank correlation coefficients $(\boldsymbol{\rho})$. If highly correlated $(\rho$ $\geq 0.6$ ), the variable with the lowest explanatory power (based on pseudo $\mathrm{R}^{2}$ ) in the univariable analysis was omitted from further analysis. The multivariable logistic model was reduced by manual backward elimination until all remaining variables had $P \leq 0.05$. All variables excluded were then reentered one by one and kept if $P$-value was $\leq 0.05$ or if the parameter estimate of another variable changed more than $20 \%$ (as indicative of confounding; Dohoo et al., 2009). Biologically plausible 2 -way interactions between variables in the reduced model were tested one by one with the intention to keep them if the $P$-value was $\leq 0.05$.

The fit of the model was evaluated by goodness-offit tests and a receiver operating characteristic curve. Lowess curves and plots of the standardized residuals against each explanatory variable were produced to assess linearity. Observations with divergent values (i.e., $-3 \leq$ Pearson residual $\geq 3$ ) were considered outliers.

To further investigate possible multicollinearity between explanatory variables considered for the multivariable logistic regression we used multiple correspondence analysis (MCA). This also gave us an indication of which explanatory variables were associated with calf mortality, and how. In MCA, variable categories are given dimensional coordinates. The first dimension explains as much of the variation (called inertia) in the data as possible. The second dimension explains as much as possible of the remaining variation, and so on. A plot of the first 2 dimensions shows clusters of associated categories. The farther away from the intersection of the axes the clusters are located, the stronger is the association (Greenacre and Blasius, 2006). The potential explanatory variables were split into 3 categories based on quartiles ( $\mathbf{Q}$; minimum to Q1, Q2 to Q3, and Q4 to maximum) and included as active variables (used to estimate the coordinates in the dimensions). The outcome variable, calf mortality, was included as a passive variable (only illustrative) with 2 classes (low and high).

\section{RESULTS}

\section{Descriptive Statistics}

The median mortality risk for all large herds in Sweden [i.e., a herd size of $\geq 140$ (year 2008/2009) and $\geq 160$ (year 2009/2010); $\mathrm{n}=178$ ], enrolled in the SOMRS was $3.0 \%$ (range of 0 to $18.23 \%$ ) in 2009/2010. Of those 178, 28 were HM herds and 29 were LM herds, as described above. For LM herds, the calf mortality risk ranged from 0 to 1.46 (median $=0.66)$ in $2008 / 2009$ and from 0 to $1.48($ median $=0.67)$ in $2009 / 2010$. For HM herds, the calf mortality risk ranged from 3.57 to 11.52 (median $=6.15$ ) in $2008 / 2009$ and from 5.88 to 18.23 (median $=8.39$ ) in 2009/2010. Median age at death was $28 \mathrm{~d}$ for HM and $37 \mathrm{~d}$ for LM herds. Descriptive statistics of the 57 (28 HM and $29 \mathrm{LM}$ ) herds identified as having either HM or LM risk are presented in Tables 1 and 2 .

\section{Multiple Correspondence Analyses}

The result of the final MCA is presented in Figure 1. The first 2 dimensions accounted for $54.1 \%$ of the variation (33.5\% in dimension 1 and $20.6 \%$ in dimension 2). The variables with the largest contribution in dimension 1 were low logarithm of BMSCC (0.18), high logarithm of BMSCC (0.10), high average age in sold bull calves (0.09), and high UHS (0.09). High herd size (0.24), high number of cows per year (0.11), low milk 
yield (0.07), and high average age at first calving (0.07) had the highest contribution in dimension 2. High calf mortality risk was clustered with high proportion of purchased animals, high UHS, and buying animals from a large number of herds. Low calf mortality risk was clustered with low UHS and low age at first calving. Besides the correlations found using the Spearman rank correlation (see below), a high incidence of antibiotic treatments was clustered with a low proportion of stillborn calves and intermediate and high BMSCC were clustered with intermediate and high average age of sold bull calves, respectively. Also, low and intermediate milk yield was clustered with low and intermediate incidence of antimicrobial treatments, respectively.

\section{Logistic Regression Model}

High correlations were found between the logarithm of BMSCC and proportion of cows with UHS 6 to 9 ( $\rho$ $=0.70$ ), between the proportion of animals purchased and the number of herds that animals were bought from $(\rho=0.67)$, between herd size and cows per year $(\rho=0.82)$, and between incidence of antimicrobial treatments and incidence of mastitis $(\rho=0.87)$. The logarithm of BMSCC, proportion of purchased animals, herd size, and incidence of antimicrobial treatments had a higher pseudo coefficient of determination value and were included in the multivariable analysis.

In the multivariable logistic regression model, HM risk was associated with higher on-farm mortality rate in cows, higher incidence of antimicrobial treatments (for all animals and for systemic use), higher proportion of purchased animals, and lower average milk yield compared with LM risk (Table 3).

In the MCA, intermediate and high BMSCC were clustered with intermediate and high average age in sold bull calves, respectively. Also, low and intermediate milk yield were clustered with low and intermediate incidence of antimicrobial treatments, respectively. This could indicate multicollinearity not detected by the Spearman rank correlation. As the latter 2 variables were included in the significant multivariable model, we decided to evaluate them further. When removing "milk yield" from the logistic regression model, the odds ratio for the variable "incidence of antimicrobial treatments" changed from 1.14 to 1.08 and the variable became nonsignificant. However, when removing "incidence of antimicrobial treatments" from the logistic regression model, the odds ratio for "milk yield" changed from 0.33 to 0.45 (i.e., still significant). A tendency for interaction existed between these 2 variables, but because it was nonsignificant $(P=0.09)$, it was not further evaluated.
Neither the Hosmer-Lemeshow nor the Pearson goodness-of-fit tests indicated a significant lack of fit $(P=0.75$ and $P=0.85$, respectively). The area under the receiver operating characteristic curve was 0.89 , which indicates a good predictive ability. The covariance patterns did not identify any potentially influential important observations and, by visual examination, the explanatory variables were linearly related to the outcome.

\section{DISCUSSION}

Having an HM risk was associated with a higher on-farm mortality rate in cows, higher incidence of systemic antimicrobial treatments, higher proportion of purchased animals, and lower average milk yield compared with herds with LM risk.

\section{Average Milk Yield}

A lower average milk yield was seen in HM herds compared with LM herds. The average milk yield reflects the amount of milk actually produced by individual cows in the herd and the lower average milk yield in HM herds is, therefore, not an effect of the higher incidence of antimicrobial treatment [i.e., more milk from cows during treatment and statutory withdrawal period (waste milk)], which would lead to a lower amount of milk delivered.

The lower milk yield could be a result of HM herds having more cows with impaired udder health compared with LM herds, which was seen in the univariable regression model both as more cows with UHS 6 to 9 and higher logarithm of BMSCC. Nielsen (2009) concluded that clinical mastitis and subclinical mastitis are factors that reduce the daily milk yield and cause economic losses. In a study of more than 20,000 Finnish Ayrshire cows, the authors could conclude that an outbreak of mastitis had a long-lasting effect of lower milk yields throughout the rest of the lactation (Rajala-Schultz et al., 1999) and this association is also supported in other studies (Seegers et al., 2003; Hand et al., 2012). Milk yield is also affected by other factors, such as management, feeding, housing, other disease, and more.

\section{Incidence of Systemic Antibiotic Treatment}

High-calf-mortality herds used significantly more antibiotics than LM herds. Torsein et al. (2011) found that managers of HM herds were more prone to treat diarrheic calves with antimicrobials than managers of LM herds. In the current study, we calculated the incidence of systemic antibiotic treatment for all animals 


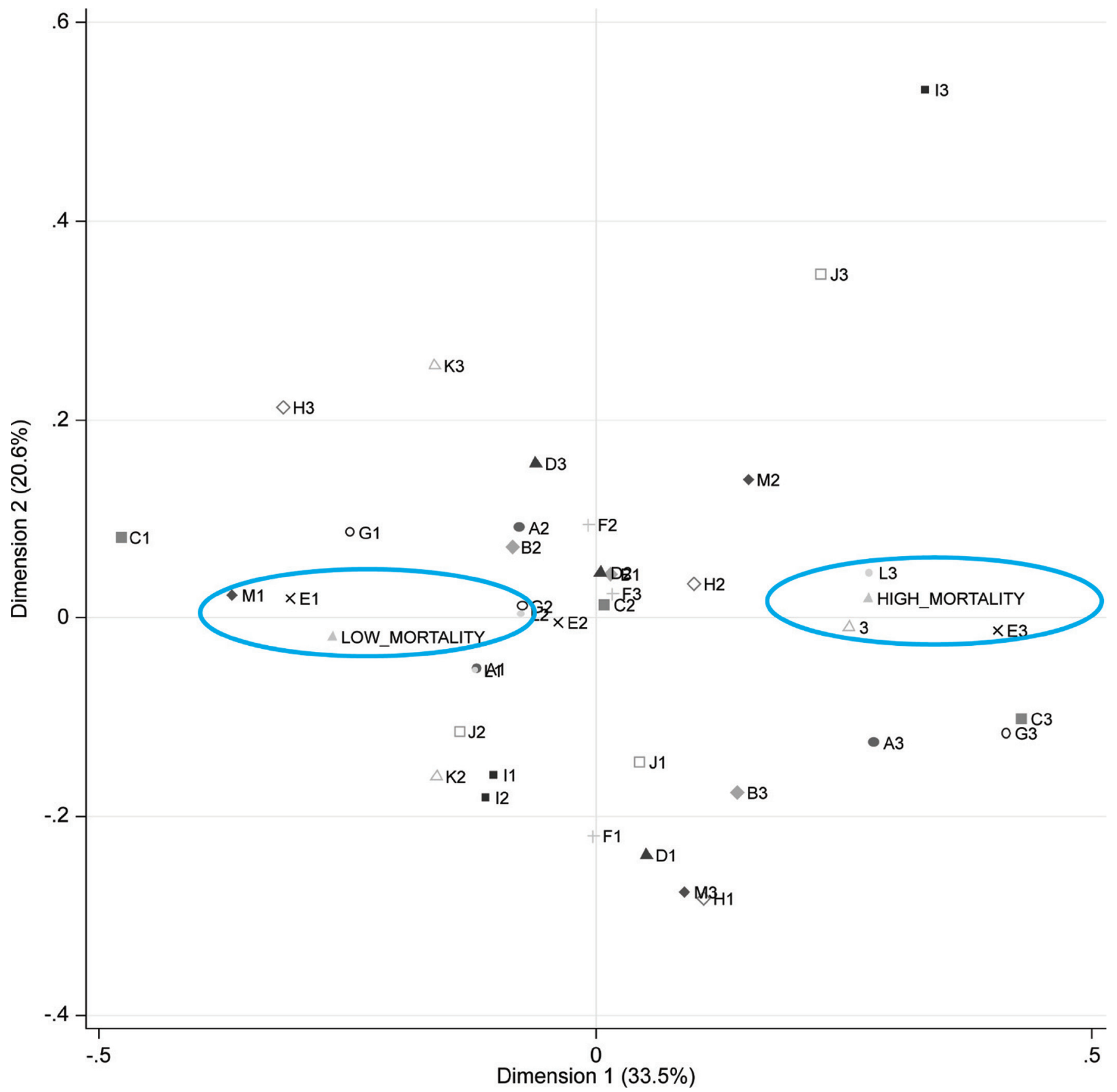

Figure 1. . Plot of the results from a correspondence analysis in a study of risk factors for high calf mortality in 57 large Swedish dairy herds. Dimension 1 is shown on the $\mathrm{x}$-axis and dimension 2 on the y-axis. Calf mortality was included as a passive variable. A = on-farm mortality $(\%) ; \mathrm{B}=$ stillbirth, heifers (\%); $\mathrm{C}=\mathrm{SCC} ; \mathrm{D}=$ incidence of antimicrobial treatments (all animals); $\mathrm{E}=$ proportion of cows with udder health score 6-9 (\%); $\mathrm{F}=$ incidence of mastitis; $\mathrm{G}=$ average age of sold bull calves (mo); $\mathrm{H}=$ average milk yield $(\mathrm{kg}) ; \mathrm{I}=\mathrm{herd}$ size; $\mathrm{J}=\mathrm{cows} /$ year; $\mathrm{K}=$ no. of herds that animals were bought from; $\mathrm{L}=$ proportion of purchased animals $(\%) ; \mathrm{M}=$ age at first calving (mo); numbers following abbreviations indicate the quartile. Color version available in the online PDF.

in the herd (veterinarian treated). No difference existed between HM and LM herds regarding the incidence of antibiotic treatment for young stock or for claw and leg disorders (data not shown), indicating that the treat- ment of cows is the predominant cause for systemic antibiotic treatment. As previously mentioned, HM herds had significantly higher logarithm of BMSCC and proportion of cows with UHS 6 to 9 in the univari- 
Table 3. Final logistic regression model of the effects of herd-level variables on being a herd with high calf mortality compared with a herd with low calf mortality in 57 large Swedish dairy herds

\begin{tabular}{|c|c|c|c|c|c|}
\hline Variable & Estimate & $\mathrm{SE}$ & $\mathrm{OR}^{1}$ & $95 \% \mathrm{CI}$ & $P$-value \\
\hline Constant & 4.22 & 3.34 & & & 0.21 \\
\hline Average milk yield, $1,000 \mathrm{~kg}$ & -1.11 & 0.42 & 0.33 & $0.14-0.75$ & 0.01 \\
\hline Incidence of antibiotic treatments & 0.13 & 0.06 & 1.14 & $1.02-1.28$ & 0.02 \\
\hline On-farm mortality $^{2}$ & 0.62 & 0.22 & 1.86 & $1.21-2.88$ & 0.01 \\
\hline Proportion of purchased animals & 0.04 & 0.02 & 1.04 & $1.01-1.08$ & 0.01 \\
\hline
\end{tabular}

${ }^{2}$ Dead and euthanized cows.

able screening. Being an HM herd was clustered with high UHS in the MCA. A possible explanation for the higher incidence of systemic antibiotic treatment could, thus, be due to the higher percentage of cows with udder health problems. However, this is not supported in our study $(P=0.15$; see Table 1$)$, but can still be part of the explanation. Claw and leg disorders could be a reason for antimicrobial treatment but no significant differences could be detected between the groups in this study $(P=0.49$; data not shown).

A higher incidence of systemic antimicrobial treatments in HM herds could mean that it is possible that calves in these herds are fed waste milk to a greater extent. Langford et al. (2003) concluded that resistance of gut bacteria to antibiotics increases with increasing concentrations of penicillin in the milk fed to dairy calves. With the present study design, however, we cannot draw any conclusions of causality.

A possible bias with regard to the apparently higher incidence of antimicrobial treatments in HM herds could be due to region (i.e., veterinarians in some regions report antibiotic usage to a lower extent; Mörk et al., 2010). In our study, HM and LM herds were evenly distributed geographically, but still, with few herds in some regions, region could still be a part of the explanation.

\section{On-Farm Mortality Rate in Cows}

Several studies have reported associations between high cow mortality and larger herds (Smith et al., 2000; Raboisson et al., 2011; Alvåsen et al., 2012), but some studies have also reported that no such associations were found (Menzies et al., 1995). One could speculate that the higher on-farm mortality among cows could be due to HM herds having older cows with impaired health compared with LM herds, but this is not supported in the data, as no differences between the groups regarding the proportion of cows in first, second, or third-or-greater parity were detected $(P=1.00,0.50$, and 0.59 , respectively). Management level is suggested as a risk factor for cow mortality (Thomsen et al., 2007;
Hallén Sandgren et al., 2009) and it is also suggested as a risk factor for calf mortality. However, the causes of high on-farm mortality rate in cows are multifactorial and are beyond the aim of the current study. Nevertheless, the association between calf and cow mortality is highly interesting and more research is needed to evaluate this, as high mortality among calves and cows is considered a welfare problem.

\section{Proportion of Purchased Animals}

The HM herds had more purchased animals than did LM herds, and this is in line with what was previously reported by Torsein et al. (2011) in a study of risk factors for calf mortality in large Swedish dairy herds. A high proportion of purchased animals also clustered with HM herds in the MCA. It may be that herds with HM have problems with replacement animals and, therefore, solve it by purchasing animals. The median age of the purchased animals was 30 and 27 mo for HM and LM herds, respectively, and $76 \%$ of the purchased animals were heifers. This indicates that it is mainly pregnant replacement animals and first-parity cows in early lactation that are bought. The proportion of purchased animals does not seem to be associated with stillbirths or on-farm mortality (data not shown), supporting the hypothesis that highmortality herds have problems with retaining sufficient numbers of replacement animals. Lack of replacement animals could have different background besides HM, including high on-farm mortality among cows, diseases, and reproductive failures (failure of getting heifers or cows, or both, pregnant). Fraser and Broom (1997) reported that $\mathrm{HM}$ and reduction in number of offspring are important indicators of poor welfare. Studies have reported that increased proportions of purchased cows were associated with increased on-farm mortality rate in cows (Thomsen et al., 2006; Raboisson et al., 2011) and this is in line with the results of our study. As shown in the univariable logistic regression model and in the MCA, purchased animals in HM herds were from significantly more herds than those in LM herds, mean- 
ing that they faced much higher risks when it comes to the introduction of new diseases to the herd, as reported by Maunsell and Donovan (2008) and Mee et al. (2012). Purchased animals could also carry resistant bacteria when introduced into the herd, which could enhance the problem with mortality in calves and cows (Adhikari et al., 2009; Mee et al., 2012), or lead to more treatments. Cows introduced into a new herd or new environment in late gestation may produce colostrum with less protective antibodies, which may be a risk for the neonate calf, as it could be less protected from diseases circulating in the new herd and, thus, be more susceptible with higher risk of mortality (Torsein et al., 2011). In the current study, we could not identify any significant differences regarding the variables associated with fertility and reproduction (see Table 1). Data on the pregnancy rates are lacking but as "culling due to poor fertility" and "cows with late ongoing AI > 120 d" did not differ (data not shown), it is unlikely that low pregnancy rate is a major reason for purchasing animals. Low mortality herds were, however, clustered with low age at first calving in the MCA. However, a Swedish longitudinal study reported an association between a rising SCC after calving and a lower probability of pregnancy at first insemination (Lomander et al., 2013).

\section{Study Design}

We defined a large herd as a herd with $\geq 160$ cows on a yearly basis. To avoid bias, we excluded herds that were expanding in herd size or recently had expanded by purchase of a large number of animals. Therefore, the inclusion criteria for herd size were set to a minimum of 140 cow-years the year prior to the study and to a minimum of 160 cow-years during the year of the study. Setting inclusion criteria on mortality risk for both years 2008/2009 and 2009/2010 reduced the risk of including herds that had experienced an occasional outbreak, leading to higher calf mortality risk that year. Hence, this should have reduced the risk of misclassification of HM herds.

It has been recommended to use 3 categories in MCA, as the association becomes more evident with 3 categories compared with 2 (Dohoo et al., 1997). We used 3 categories for the explanatory variables but only 2 for calf mortality. We could have included a third group of herds with intermediate calf mortality. However, we choose to include only the groups with HM or LM, as these 2 groups were contrasted in line with our hypothesis.

With the present study design, we can only identify associations between risk factors; no causal relationships can be drawn with this study design. Causes of calf mortality are multifactorial, and some of the risk factors identified in this study have also been reported in studies of cow mortality, as previously mentioned.

\section{Indicators}

Studies have been performed in dairy herds worldwide to develop a tool where database screening could be used to find herds with impaired animal welfare (Hallén Sandgren et al., 2009; Kelly et al., 2013). Kelly et al. (2013) reported that suitable key farmer performance indicators, able to distinguish herds with and without on-farm animal welfare problems, were not found. A more successful identification of herds with poor welfare, with up to $77 \%$ correct classification of the herds with welfare remarks, was achieved when including percentage of cows with late ongoing AI, percentage of heifers without mating or AI by 17 mo of age, and calf mortality in the age group 2 to 6 mo (Hallén Sandgren et al., 2009). The aim of our study, however, was not to investigate variables potential to use for screening purpose; instead, we focused on calf mortality from a holistic point of view to gather more knowledge of what characterizes HM and LM herds to give farmers with large dairies updated advice.

\section{CONCLUSIONS}

Herds with HM risks during d 1 to 90 were associated with higher on-farm mortality rate, lower average milk yield, higher incidence of antibiotic treatment, and a higher proportion of purchased animals. We conclude that herds with HM risk during d 1 to 90 have coexisting issues concerning cow management and health. When dealing with calf mortality problems, it can be helpful to bear in mind these coexisting issues and include analyses of the entire herd situation.

\section{ACKNOWLEDGMENTS}

The study was financially supported by the Swedish Animal Health Service (Skara, Sweden) and the Swedish University of Agricultural Sciences (Skara, Sweden).

\section{REFERENCES}

Adhikari, B., T. E. Besser, J. M. Gay, L. K. Fox, M. A. Davis, R. N. Cobbold, A. C. B. Berge, and D. D. Hancock. 2009. The role of animal movement, including off-farm rearing of heifers, in the interherd transmission of multidrug-resistant Salmonella. J. Dairy Sci. 92:4229-4238.

Alvåsen, K., M. Jansson Mörk, C. Hallén Sandgren, P. T. Thomsen, and U. Emanuelson. 2012. Herd-level risk factors associated with cow mortality in Swedish dairy herds. J. Dairy Sci. 95:4352-4362.

Brolund, L. 1990. Cellhaltens tekniska utnyttjande i kokontrollen (Technical utilization of cell count in the milk-recording service). 
Pages 40-41 in Animal health 1988/89. Swedish Association for Livestock Breeding and Production, Eskilstuna, Sweden.

Dohoo, I. R., C. Ducrot, C. Fourichon, A. Donald, and D. Hurnik 1997. An overview of techniques for dealing with large numbers of independent variables in epidemiologic studies. Prev. Vet. Med. 29:221-239.

Dohoo, I., W. Martin, and H. Stryhn. 2009. Veterinary Epidemiologic Research. 2nd ed. VER Inc., Charlottetown, PE, Canada.

Fraser, A. F., and D. M. Broom. 1997. Farm Animal Behaviour and Welfare. CAB International, Wallingford, UK.

Gidekull, M., C. Hallén Sandgren, A. Lindberg, C. Svensson, and M. Törnquist. 2006. Kalvdödlighet i stora svenska mjölkkobesättningar (Calf mortality in large Swedish dairy herds). Page 197-198 in Proc. Veterinärmötet 2006. Sveriges veterinärförbund Sveriges veterinärmedicinska sällskap, Uppsala, Sweden.

Greenacre, M., and J. Blasius, editors. 2006. Multiple Correspondence Analysis and Related Methods. Chapman \& Hall/CRC, Boca Raton, FL.

Gulliksen, S. M., K. I. Lie, T. Løken, and O. Østerås. 2009. Calf mortality in Norwegian dairy herds. J. Dairy Sci. 92:2782-2795.

Hallén Sandgren, C., A. Lindberg, and L. J. Keeling. 2009. Using a national dairy database to identify herds with poor welfare. Anim. Welf. 18:523-532.

Hand, K. J., A. Godkin, and D. F. Kelton. 2012. Milk production and somatic cell counts: A cow-level analysis. J. Dairy Sci. 95:1358 1362 .

James, R. E., M. L. McGilliard, and D. A. Hartman. 1984. Calf mortality in Virginia dairy herd improvement herds. J. Dairy Sci. 67:908-911

Jenny, B. F., G. E. Gramling, and T. M. Glaze. 1981. Management factors associated with calf mortality in South Carolina dairy herds. J. Dairy Sci. 64:2284-2289.

Kehoe, S. I., B. M. Jayarao, and A. J. Heinrichs. 2007. A survey of bovine colostrum composition and colostrum management practices on Pennsylvania dairy farms. J. Dairy Sci. 90:4108-4116.

Kelly, P. C., S. J. More, M. Blake, I. Higgins, T. Clegg, and A. Hanlon. 2013. Validation of key indicators in cattle farms at high risk of animal welfare problems: A qualitative case-control study. Vet. Rec. 172:314.

Lance, S. E., G. Y. Miller, D. D. Hancock, P. C. Bartlett, L. E. Heider, and M. L. Moeschberger. 1992. Effects of environment and management on mortality in preweaned dairy calves. J Am. Vet. Med. Assoc. 201:1197-1202.

Langford, F. M., D. M. Weary, and L. Fisher. 2003. Antibiotic resistance in gut bacteria from dairy calves: A dose response to the level of antibiotics fed in milk. J. Dairy Sci. 86:3963-3966.

Lomander, H., C. Svensson, C. Hallén-Sandgren, H. Gustafsson, and J. Frössling. 2013. Associations between decreased fertility and management factors, claw health, and somatic cell count in Swedish dairy cows. J. Dairy Sci. 96:6315-6323.

Maunsell, F., and G. A. Donovan. 2008. Biosecurity and risk management for dairy replacements. Vet. Clin. North Am. Food Anim. Pract. 24:155-190.

Mee, J. F., T. Geraghty, R. O'Neill, and S. J. More. 2012. Bioexclusion of diseases from dairy and beef farms: Risks of introducing infectious agents and risk reduction strategies. Vet. J. 194:143-150.
Menzies, F. D., D. G. Bryson, T. McCallion, and D. I. Matthews. 1995. A study of mortality among suckler and dairy cows on Northern Ireland in 1992. Vet. Rec. 137:531-536.

Mörk, M. J., C. Wolff, A. Lindberg, I. Vågsholm, and A. Egenvall. 2010. Validation of a national disease recording system for dairy cattle against veterinary practice records. Prev. Vet. Med. 93:183-192.

Nielsen, C. 2009. Economic impact of mastitis in dairy cows. Page 81. Doctoral Thesis. Swedish University of Agricultural Sciences, Uppsala, Sweden.

Nielsen, L. A. H., A. Glasius, A. Fogh, and F. Skjøth. 2002. Dødelighed hos kalve af malkerace (Mortality in dairy calves). Report no. 102. Landbrugets Rådgivningcenter, Dansk Kvaeg, Aarhus, Denmark.

Olsson, S.-O., P. Baekbo, S. Ö. Hansson, H. Rautala, and O. Østerås. 2001. Disease recording systems and herd health schemes for production diseases. Acta Vet. Scand. Suppl. 94:51-60.

Olsson, S.-O., S. Viring, U. Emanuelsson, and S.-O. Jacobsson. 1993. Calf diseases and mortality in Swedish dairy herds. Acta Vet. Scand. 34:263-269.

Ortiz-Pelaez, A., D. G. Pritchard, D. U. Pfeiffer, E. Jones, P. Honeyman, and J. J. Mawdsley. 2008. Calf mortality as a welfare indicator on British cattle farms. Vet. J. 176:177-181.

Raboisson, D., E. Cahuzac, P. Sans, and G. Allaire. 2011. Herd-level and contextual factors influencing dairy cow mortality in France in 2005 and 2006. J. Dairy Sci. 94:1790-1803.

Rajala-Schultz, P. J., Y. T. Gröhn, C. E. McCulloch, and C. L. Guard. 1999. Effects of clinical mastitis on milk yield in dairy cows. J Dairy Sci. 82:1213-1220.

Seegers, H., C. Fourichon, and F. Beaudeau. 2003. Production effects related to mastitis and mastitis economics in dairy cattle herds. Vet. Res. 34:475-491.

Smith, J. W., L. O. Ely, and A. M. Chapa. 2000. Effect of region, herd size, and milk production on reasons cows leave the herd. J. Dairy Sci. 83:2980-2987.

Svensson, C., A. Linder, and S. O. Olsson. 2006. Mortality in Swedish dairy calves and replacement heifers. J. Dairy Sci. 89:4769-4777.

Swedish Dairy Association. 2012. Husdjursstatistik (Animal health: Annual report from the animal health section) [In Swedish]. Vol. 2014-01-02. Swedish Dairy Association. Accessed Feb. 1, 2014 http://www.svenskmjolk.se/Om-oss/Publikationer/Statistik/Husdjursstatistik/.

Thomsen, P. T., A. M. Kjeldsen, J. T. Sørensen, H. Houe, and A. K. Ersbøll. 2006. Herd-level risk factors for the mortality of cows in Danish dairy herds. Vet. Rec. 158:622-626.

Thomsen, P. T., S. Østergaard, H. Houe, and J. T. Sørensen. 2007. Loser cows in Danish dairy herds: Risk factors. Prev. Vet. Med. 79:136-154.

Torsein, M., A. Lindberg, C. H. Sandgren, K. P. Waller, M. Törnquist, and C. Svensson. 2011. Risk factors for calf mortality in large Swedish dairy herds. Prev. Vet. Med. 99:136-147.

Wathes, D. C., J. S. Brickell, N. E. Bourne, A. Swali, and Z. Cheng. 2008. Factors influencing heifer survival and fertility on commercial dairy farms. Animal 2:1135-1143. 